\title{
Two-step hybrid process of movable part inside glass substrate using ultrafast laser
}

Jeongtae Kim ${ }^{1 \dagger}$, Sung-ll Kim ${ }^{2 \dagger}$, Yeun-Ho Joung ${ }^{1}$, Jiyeon Choi ${ }^{2^{*}}$ and Chiwan Koo ${ }^{1 *}$

\begin{abstract}
We demonstrate a two-step hybrid process for fabricating movable parts inside glass substrate using the selective laser-induced etching (SLE) process that is consisted of laser-direct writing and wet chemical etching. To obtain an influence by the optical characteristics of a glass substrate when fabricating a 3D microstructure using the SLE, we analyzed the relationship of their dimensions between the designed and the fabricated devices. Two 3D microfluidic devices are designed and fabricated on glass substrates as the demonstrations of the hybrid process: a 3D microfluidic valve device with a movable plug and a 3D microfluidic mixer with a rotatable impeller and multilayer microchannels. The valving plug and the impeller of each device are successfully moved and rotated. The smallest structure is a pillar of the impeller device, and its size is $29 \mu \mathrm{m}$ (diameter) $\times 277 \mu \mathrm{m}$ (height). We expect this study to be extended to potential applications in 3D glass microfabrication and microfluidic systems.
\end{abstract}

Keywords: Movable part, Ultrafast laser, Hybrid fabrication, Glass, Microfluidic system

\section{Introduction}

Microfluidic devices, also known as lab-on-a-chip, and $\mu$-TAS are the analysis devices that can manipulate a variety of samples using their microchannels. Due to the microscale, minuscule volumes of samples are required, which is cost-effective and provides fast response times. Based on these advantages, the microfluidic analysis devices are attractive when using point-of-care testing, such as biological and chemical applications, medical diagnostics, food safety management, environmental monitoring, and viral infections [1]. These microfluidic devices have been fabricated by the conventional MEMS process, such as soft lithography or hot embossing with transparent polymer-based materials, because of ease of fabrication. However, the polymers are weak to the organic solvent, absorb molecules of tiny sizes, and have relatively higher autofluorescence than glasses [2].

\footnotetext{
*Correspondence: jchoi@kimm.re.kr; cwankoo@hanbat.ac.kr

†Jeongtae Kim and Sung-II Kim are co-first authors

${ }^{1}$ Department of Electronic Engineering, Hanbat National University, Daejeon, Republic of Korea

2 Department of Laser and Electron Beam Technologies, Korea Institute of Machinery and Materials, Daejeon, Republic of Korea
}

Glass is good alternative material. Because glass has high resistance to mechanical stress and high chemical resistance, glass microfluidic devices can resist varying chemical materials $[3,4]$. As mentioned, glass can be applied to optical devices due to its low autofluorescence [5]. Due to its high chemical durability, the fabrication of glass microfluidic devices is difficult and expensive. In addition, the conventional MEMS process, which is based on two-dimensional (2D) semiconductor fabrication techniques, has limitations to resolve the complexity and the difficulty to fabricate a multi-layer structure [6-8]. To solve these problems, recently, ultrafast laser processing was introduced [9]. Selective laser-induced etching (SLE), which is a hybrid process composed of ultrafast laser modification of glass and subsequent wet etching, is considered to be one of the most promising technologies for three-dimensional (3D) micro structuring inside glass $[1,10]$. Laser modification of glass creating nano-gratings and nano-porous expedites the etching process, thus modified glass has a higher etch rate than pristine glass [11]. When immersed in an etchant (such as potassium hydroxide $(\mathrm{KOH})$ or hydrofluoric acid (HF)), the modified regions are selectively dissolved 
faster, resulting in the monolithic 3D microstructures in the glass. Therefore, unlike the multi-step MEMS processes, including photolithography, masking, bonding, plating, SLE provides an efficient means of 3D fabrication with a simple two-step manufacturing process.

Recent SLE studies include various microstructures with different glass compositions, including fused silica [12, 13], alumino-borosilicate glass [14], and borosilicate glass $[15,16]$. Although most previous studies have been limited to the fabrication of 2D planar structures, nowadays, studies on 3D integrated systems, including $3 \mathrm{D}$ embedded movable structures, are being actively conducted [17-19].

We have reported a 3D glass microfluidic device with multi-layer channels using the SLE process [20]. In this study, we demonstrate the fully three-dimensional movable structures inside the glass as well as the evaluation of the operation of devices qualitatively and quantitatively. Fused silica was chosen for all experiments to utilize its high etching selectivity, which is proven to be at least a hundred to thousand times higher than other glass compositions [21]. Therefore, high resolution for the smooth operation of movable parts was readily achieved with fused silica [22-25]. In order to increase the fabrication precision of 3D glass microfluidic devices, a two-step hybrid process was used with refractive index offset.

With an improved two-step hybrid process, we demonstrated a 3D glass microfluidic valve device with a movable plug and a 3D glass microfluidic mixer with a rotatable impeller and multilayer microchannels. In the valve unit, the valve plug is located inside the valve chamber connected by three microchannels. Valve operation was tested by applying pressure and vacuum. The impeller mixer has a rotatable impeller with a shaft inside the chamber. The impeller was fixed with a holding cap. A mixing test with bromothymol blue (BTB) solution was performed to show the application of the impeller device. The SLE process has demonstrated its ability to produce high-resolution moving parts with greater manufacturing precision by presenting the successful manufacture of compact precision shafts and impellers. It will open new avenues for potential applications of glass microfabrication.

\section{Preliminary test}

We have already reported that the optimization of SLE for the fabrication of 3D glass microfluidic devices [20]. In order to precisely control the location of the interaction with laser and in-volume glass substrate, we analyzed a relationship between the dimensions of the designed and the fabricated devices. The width and height of the two models were the same, except for tolerance by a wet-etch process. On the contrary, the fabricated depth was larger than the designed depth and increased linearly concerning the designed depth as shown in Fig. 1. The inclination was about 1.47 and we experimentally obtained the effective refractive index of the fused silica glass used in this work. As a result, to fabricate the 3D device with the desired dimensions, the depth must be modified as the offset by the refractive index of the fused silica substrate so that the ratio of the design to the desired depth is the same as its effective refractive index.

\section{Experiments \\ Design of a 3D glass microfluidic valve device with a movable plug}

Designs and cross-section of A 3D glass microfluidic valve device with a movable plug are shown in Fig. 2A, B. The glass valve has three microfluidic channels and these channels are connected with a valve chamber. Inside the chamber, the microfluidic valve is located. The total length and height of the 3D glass microfluidic valve were designed as $2.9(\mathrm{~W}) \times 2.1(\mathrm{H}) \mathrm{mm}^{2}$. The three channels were the length of $0.85 \mathrm{~mm}$ and the width of $50 \mu \mathrm{m}$. Considering the effect of the reflective index, the vertical cross-section of these channels was oval in shape to fabricate the circular cross-section, resulting in the height of about $34 \mu \mathrm{m}$. The valve chamber and plug were truncated quadrangular pyramid shape. The bottom and top surface were rectangular with $250(\mathrm{~W}) \times 172(\mathrm{H})$ and 145 $(\mathrm{W}) \times 100(\mathrm{H}) \mu \mathrm{m}^{2}$, respectively, and the height of the chamber was $600 \mu \mathrm{m}$. To structure the space in which the valving plug can be movable, the valving plug has been designed at the height of $400 \mu \mathrm{m}$. To separate the valve and plug after etching, the $30 \mu \mathrm{m}$ modification layer was added between the valve and the plug designs, as shown in Fig. 2B. The dimensions of the valve device are shown in Fig. 2A, B in detail.

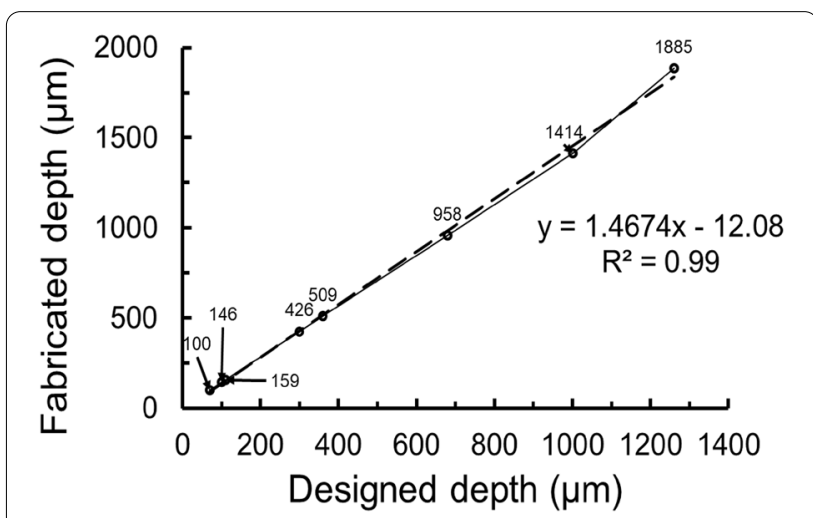

Fig. 1 A relationship between the depths of design and the fabricated device. The inclination was about 1.47, and it means the effective refractive index of the fused silica glass obtained in this work 

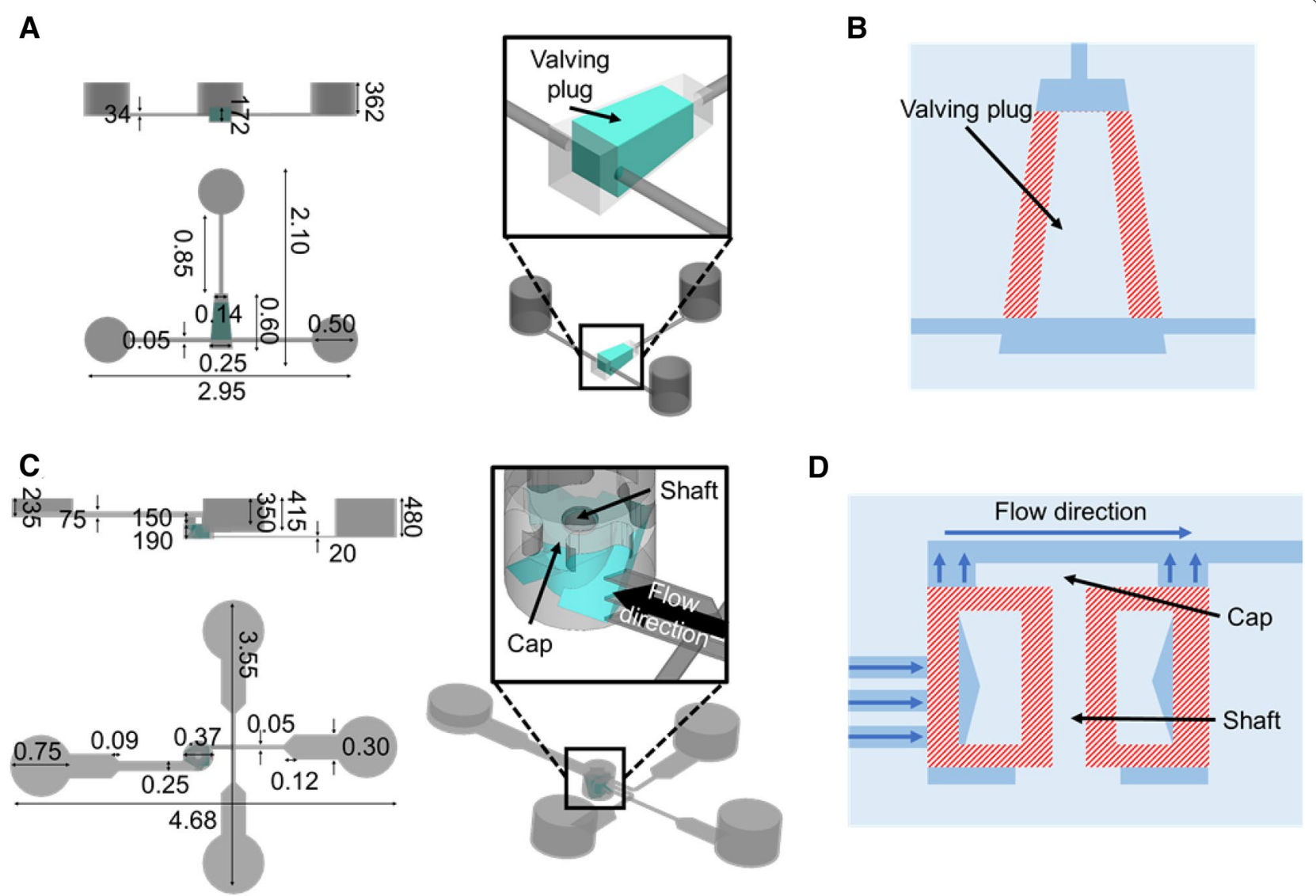

Fig. 2 Schematics of a 3D glass microfluidic valve device and a 3D glass microfluidic impeller device with multi-layer microchannels. A The top, side, and bird views of the valve device. B The cross section of the valve chamber. CThe top, side, and bird views of the impeller device. D The cross section of the impeller chamber. The red dashed areas mean the separation layer to fabricate movable parts

\section{Design of a 3D glass microfluidic mixer with a rotatable impeller and multi-layer microchannels}

A 3D glass microfluidic mixer with a rotatable impeller and multi-layer channels is shown in Fig. 2C. The 3D glass microfluidic mixer is composed of three-layer inlets, an impeller and impeller chamber, and an outlet. The inlets and the outlet channels were composed of buffer channels and connection channels with the impeller chamber. The widths of the buffer and the connection channel were 300 and $100 \mu \mathrm{m}$, respectively. The interfaces of these two channels were designed as a tapered structure in the length of $125 \mu \mathrm{m}$ at the inlet sides and in the length of $90 \mu \mathrm{m}$ at the outlet side. The total length of the top and the middle inlets was equal to $1050 \mu \mathrm{m}$ and these were bent $90^{\circ}$ anticlockwise and clockwise with respect to the bottom layer, respectively. The total length of the bottom layer was $1230 \mu \mathrm{m}$. The impeller chamber was cylindrical and a diameter of $375 \mu \mathrm{m}$ and a height of $350 \mu \mathrm{m}$. The impeller was designed as a three-blade structure in about $34^{\circ}$ to fabricate the inclination of $45^{\circ}$, considering the effect by the refractive number. Its diameter was
$315 \mu \mathrm{m}$ by applying the separation layer between the impeller and its chamber, as shown in Fig. 2D. In order to be able to rotate the impeller, the shaft of the impeller was structured at the center of the chamber with the separation layer as $30 \mu \mathrm{m}$. In addition, to prevent the friction between the chamber, the impeller, and the holding cap, which holds the impeller in the chamber, the $30 \mu \mathrm{m}$ separation layer was added. The holding cap was a cross shape to flow out the fluids with the height of $75 \mu \mathrm{m}$ and connected with the outlet. More details about dimensions showed in Fig. 2C, D.

\section{Two-step hybrid process}

Two-step hybrid process consists of physical and chemical steps, as shown in Fig. 3A. The detailed fabrication procedure has been described elsewhere [20]. All devices demonstrated in this study were fabricated using premium-grade fused silica (JMC glass, Ansan, KOREA). An ultrafast laser (Satsuma HP2, Amplitude laser, Pessac, FRANCE) at a center wavelength of $1030 \mathrm{~nm}$, was used for localized modification. Laser 


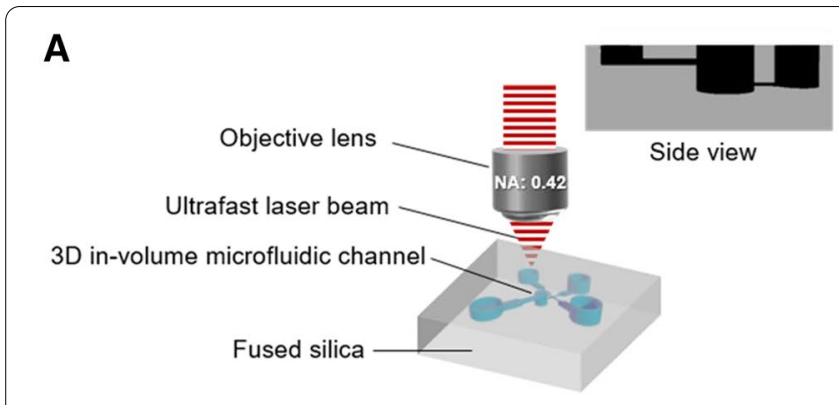

Step 1. Laser in-volume modification

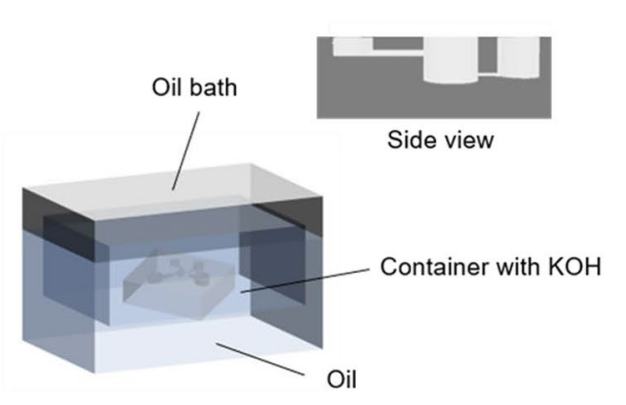

Step 2. Wet etching (KOH)
B

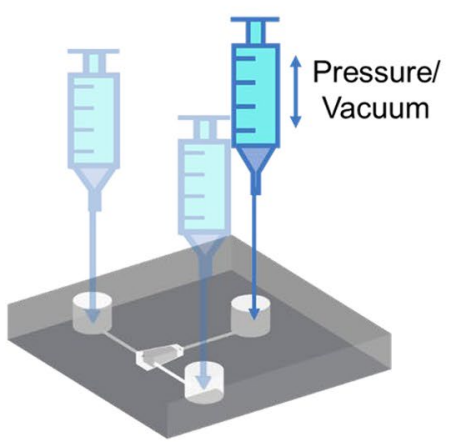

C

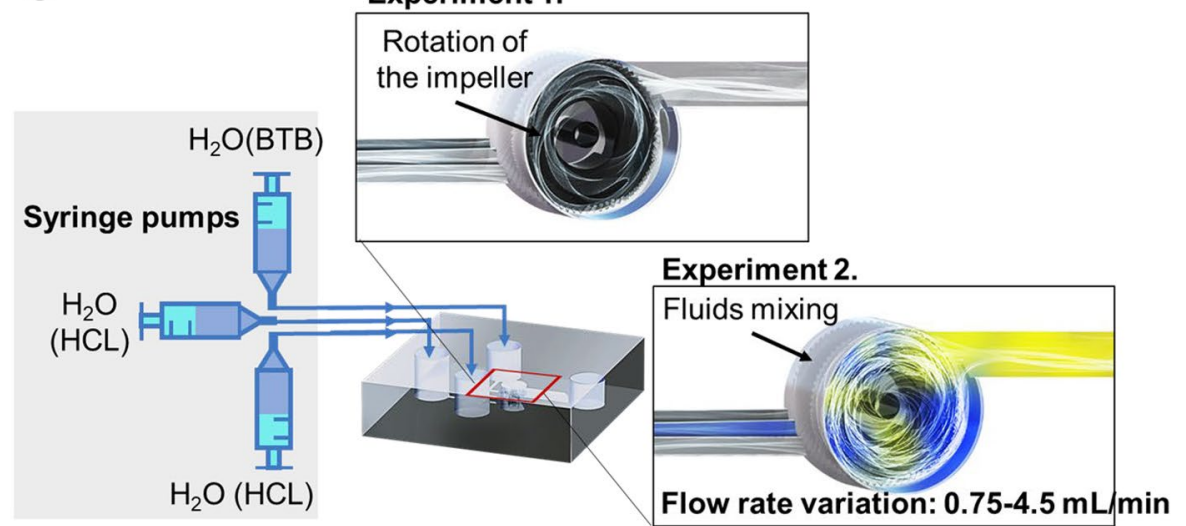

Fig. 3 Fabrication of 3D glass microfluidic devices using a two-step hybrid process and setups for observations of the movable parts. A A two-step hybrid process. B Setup of the valving plug movement test. C Setups of the impeller rotation and the mixing performance. In $\mathbf{A}$, the 3D design was calibrated to reflect the optical properties before laser-direct writing

process parameters for high etching selectivity conditions were controlled in terms of pulse width: 1 ps, pulse repetition rate: $500 \mathrm{kHz}$, and pulse energy $400 \mathrm{~nJ}$ [20]. The ultrafast laser beam was deflected by a pair of Galvano mirrors (DynAXIS, SCANLAB, Puchheim, GERMANY) and then focused using a $50 \times$, NA 0.42 objective lens (M plan Apo 50X, Mitutoyo, Kawasaki, JAPAN) in a high-speed direct writing system. The polarization of the beam was kept parallel with $x$-axis. In addition, for precise layer-by-layer processing, an air bearing Z-axis stage (BMZA-300, Bluemotion Tech, Hwaseong, KOREA) and a motorized linear motion XY-axis stage (ALS130-100XY, Aerotech, Pittsburgh, USA) were utilized. With 5-axis synchronization control through a dedicated controller (A3200, Aerotech, Pittsburgh, USA), the velocity of the stage was set to $200 \mathrm{~mm} / \mathrm{s}$ and the position error is within $100 \mathrm{~nm}$. The laser path of the 3D design file (STL format) is automatically transformed by the 3D fabrication software (3Dpoli, Femtika, Vilnius, Lithuania) into 2D vector data, such as slicing and hatching with scales of $10 \mu \mathrm{m}$ and $15 \mu \mathrm{m}$, respectively. In the chemical etching step, a
Teflon container filled with an $8 \mathrm{~mol} / \mathrm{L}$ concentration of potassium hydroxide $(\mathrm{KOH})$ was maintained at $100{ }^{\circ} \mathrm{C}$ by immersion in a digital purge-controlled oil bath (WHB-6, DAIHANSCIENTIFIC, Daejeon, KOREA) filled with heat transfer fluid (Therminol D12 ${ }^{\circledR}$, EASTMAN, Tennessee, USA). The laser-irradiated glass was etched for $12-15 \mathrm{~h}$.

\section{Experimental setups}

Observation of the valving plug of the 3D glass microfluidic valve device

Figure 3B shows the test setup of a movement of the valve device. To observe the movement of the valving plug inside the 3D glass microfluidic valve device, pressure and vacuum were applied to the device. To apply the pressure and vacuum, one side of the silicon tube was connected to the 3D glass microvalve device with the PDMS block. Another side was connected with a syringe using a syringe needle. The movement of the valving plug was observed with an optical microscope by applying the pressure and the vacuum. 


\section{Rotation of the 3D glass microfluidic impeller device with the multi-layer microchannels}

Figure $3 \mathrm{C}$ shows the impeller rotation test. To show that the impeller can be rotated by the flow, the water was injected into the device by syringe pumps. Three $10 \mathrm{ml}$ syringes were used to insert the water. To connect the syringe with the $3 \mathrm{D}$ microfluidic device, the silicon tubes were connected with the syringes by the syringe needles and another side of the silicon tubes was linked with the PDMS block. The rotation of the impeller was observed using the optical microscope by increasing the flow rate of the syringe pump and recorded by the video camera equipped with the optical microscope. Moreover, to show the application availability as a microfluidic mixer, the mixing test was conducted. In order to obtain the mixing performance, the bromothymol-blue (BTB) dissolved in sodium hydroxide, that is $0.5 \%(\mathrm{~g} / \mathrm{v})$, was introduced at the middle layer inlet and the $0.05 \%(\mathrm{v} / \mathrm{v})$ hydrochloric acid was inserted at the top and bottom layer inlets. The mixing performance was captured by the optical microscope while increasing the flow rates of the syringe pump as $0.25 \mathrm{~mL} / \mathrm{min}$.

\section{Results}

\section{Fabricated 3D glass microfluidic devices with movable} parts

As following Fig. 4 shows the fabricated 3D glass microfluidic devices. The fabricated valve device was the 2.98
$(\mathrm{W}) \times 2.14(\mathrm{H}) \mathrm{mm}^{2}$, the valve chamber was $289(\mathrm{~W})$ $\times 641(\mathrm{H}) \mu \mathrm{m}^{2}$, and the valving plug was $154(\mathrm{~W}) \times 349$ $(\mathrm{H}) \mu \mathrm{m}^{2}$, as shown in Fig. 4A. The next Fig. 4B shows the fabricated 3D glass microfluidic impeller device with multi-layer microchannels. The total size of the impeller devices was $4.78(\mathrm{~W}) \times 3.63(\mathrm{H}) \mathrm{mm}^{2}$, and all lengths of the three inlets were about $1239 \mu \mathrm{m}$. The width of the buffer and the connection channel interface was the same as the designed width as $100 \mu \mathrm{m}$. The diameter of the impeller chamber, the impeller shaft, and the impeller were 381,306 , and $29 \mu \mathrm{m}$. From the impeller shaft result, it is showed that the SLE process can be fabricated 29 (D) $\times 277(\mathrm{H}) \mu \mathrm{m}^{2}$ pillar structure. The impeller size was $306(\mathrm{D}) \times 215(\mathrm{H}) \mu \mathrm{m}^{2}$. The outlet length was $1267 \mu \mathrm{m}$ similar to the length of inlets. However, the start points of the tapered structure by wet etch were not positioned at the center of the device. The reason was that the top and middle layer was etched too quickly. To fix this problem, the design was modified that the length of the bottom inlet and the outlet was decreased as 150 and $200 \mu \mathrm{m}$, respectively. The modified device showed in Fig. $4 \mathrm{C}$ with details.

\section{Movability test of 3D glass microfluidic devices}

In order to move the valving test, the pressure and vacuum were applied to the valve device by the syringe pump. As shown in Fig. 5A-C, the position of the valving plug was changed by the direction of the air pressure/

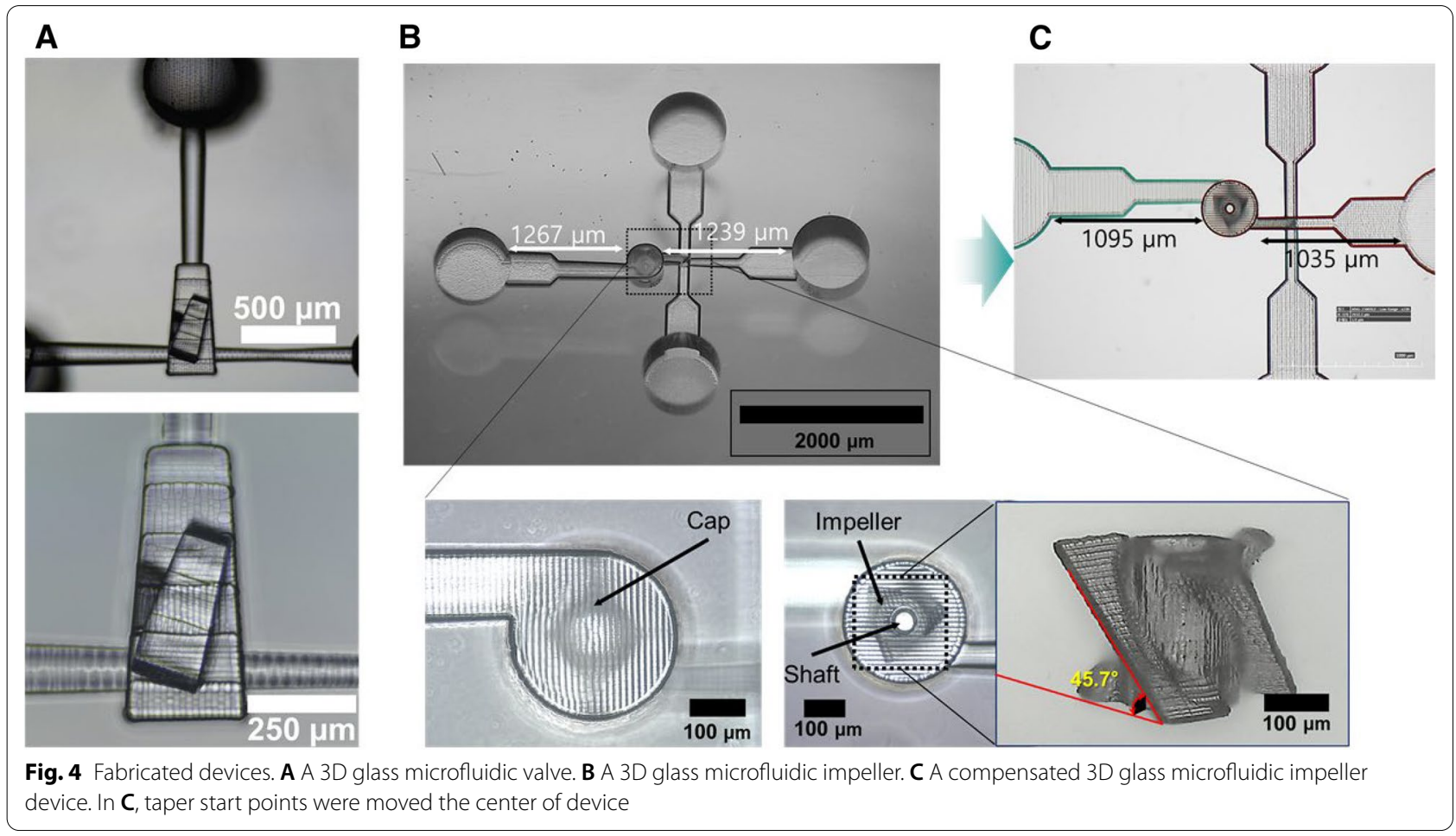


A

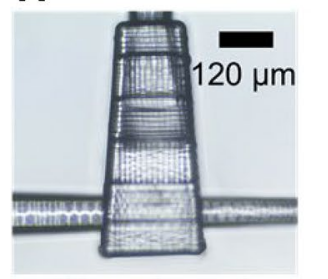

Top closed

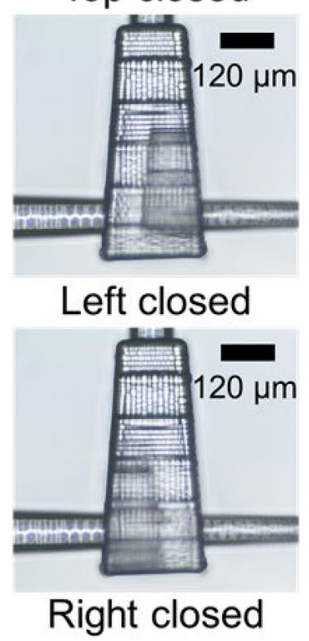

B
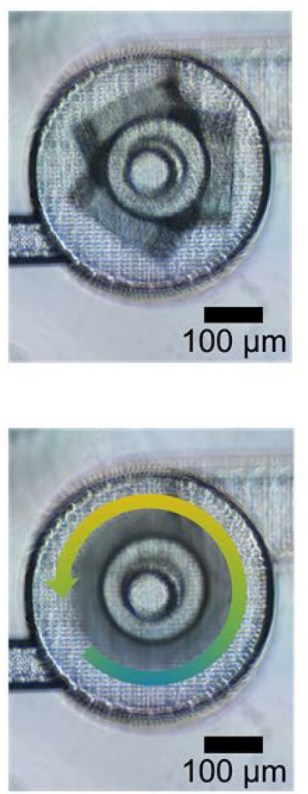

C
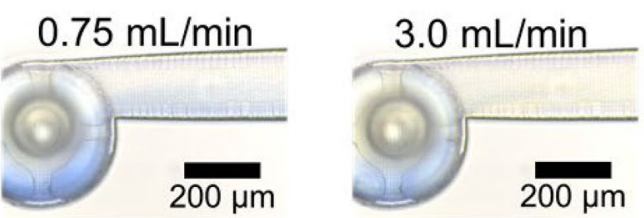

$3.75 \mathrm{~mL} / \mathrm{min}$
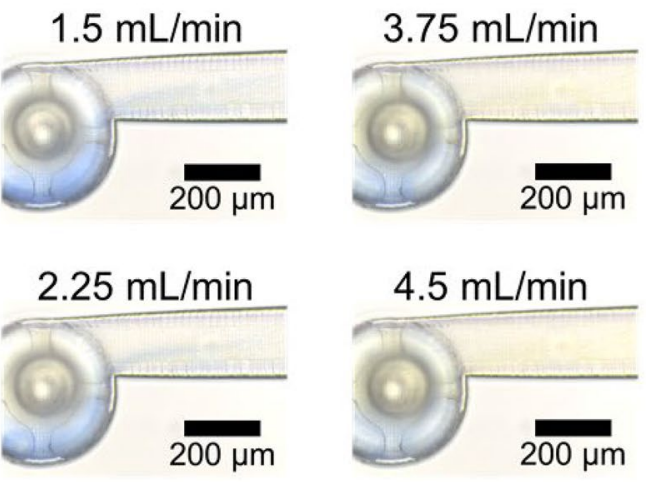

Fig. 5 Movability test results. A Valving operations. B Impeller rotation. C Mixing performance

vacuum. When applying the vacuum at the middle channel of the device, the bottom side channels were connected like Fig. 5A. When the pressure was applied to the right channel or the left channels, the middle channel was connected with the channels where the pressure was applied. These showed in Fig. 5B, C. As a result, it is shown that the $3 \mathrm{D}$ valve structure inside the glass can be fabricated by the SLE process. However, the valve device is needed to be optimized because the gap between the valve chamber and the valving plug was too wide as shown in Fig. 5A.

Next, to observe the rotation of the impeller inside the glass by the fluid flow, the BTB solution was injected into the impeller mixer using the syringe pump. Firstly, to find the minimum flow rate to revolve the impeller, the flow rate of the syringe pump was set to $0.1 \mathrm{~mL} / \mathrm{min}$. Because the number of syringes was three, the total flow rate is three times higher than the flow rate of the syringe pump. At the initial $0.3 \mathrm{~mL} / \mathrm{min}$ flow rate, the impeller was not rotated by the flow. Although the flow rate was increased by $0.15 \mathrm{~mL} / \mathrm{min}$, the impeller was still stopped before the flow rate was reached at $0.75 \mathrm{~mL} / \mathrm{min}$. As a result, the minimum flow rate for rotating the impeller was $0.75 \mathrm{~mL} / \mathrm{min}$. Due to the turbulence by the rotation of the impeller, the mixing can be achieved inside the mixing chamber. Based on this, to obtain the availability as a micromixer, the mixing performance was observed using an optical microscope while changing the flow rate by $0.25 \mathrm{~mL} / \mathrm{min}$. As shown in Fig. $5 \mathrm{C}$, the blue streamline could be observed at $0.75 \mathrm{~mL} / \mathrm{min}$. By increasing the flow rate more and more, the blue streamline was gradually disappeared. When the flow rate was reached at $3.75 \mathrm{~mL} /$ min, the outlet channel was yellow perfectly. It means that the three fluids were perfectly mixed. Although the blue streamline remained at $2.25 \mathrm{~mL} / \mathrm{min}$, there was no blue streamline at the center of the outlet channel. It means that the fluids were perfectly mixed at $2.25 \mathrm{~mL} /$ min. To make sure that the actual mixing performance, the mixing index was analyzed. The mixing index was calculated using the following formula based on the standard deviation [19].

$$
M I=1-\frac{\sqrt{\frac{1}{N} \sum_{k=1}^{N}\left(I_{k}-\bar{I}_{O}\right)^{2}}}{\bar{I}_{O}}
$$

As a result, the mixing index was about 0.93 at $2.25 \mathrm{~mL} / \mathrm{min}$, and it can be said that the minimum mixing flow rate is $2.25 \mathrm{~mL} / \mathrm{min}$. But, if a more uniform mixture is required, then the flow rate of $3.75 \mathrm{~mL} / \mathrm{min}$ is recommended.

Our group has already been reported that the 3D glass micromixer with the impeller [19]. Its mixing efficiency 
was showed $90 \%$ except for $1.5 \mathrm{~mL} / \mathrm{min}$. The maximum mixing efficiency were $93 \%$ at $4.5 \mathrm{~mL} / \mathrm{min}$. Because it is focused on the high-throughput test, the minimum flow rate was relatively higher. To reduce the required flow rate to achieve higher mixing efficiency, the impeller mixer of this study is scaled down as half of the previous devices. Due to this, the flow rate with respect to the mixing efficiencies was reduced by half of the previous results. As a result, this study's microfluidic mixer was achieved the same mixing efficiency at the 2 times lower flow rate than the previous one. Thus, it can be applied to the low flow rate application.

\section{Discussions}

The glass-based 3D microfluidic devices with movable parts were fabricated by the SLE process, which is a two-step hybrid process of laser direct writing by an ultrafast laser and wet-etch with $\mathrm{KOH}$. The fabricated valve and impeller mixer were $2.98(\mathrm{~W}) \times 2.14(\mathrm{H})$ and $4.78(\mathrm{~W}) \times 3.63(\mathrm{H}) \mathrm{mm}^{2}$. The impeller and the shaft that is the smallest part of the impeller device were 306 (D) $\times 215(\mathrm{H})$ and $29(\mathrm{D}) \times 277(\mathrm{H}) \mu \mathrm{m}^{2}$. To obtain the movability of the in-glass parts, the $3 \mathrm{D}$ glass microfluidic valve device and the impeller device with multi-layer microchannels were demonstrated. In the movement test of the valving plug, it was successfully moved by the pressure and the vacuum. In the rotation test of the impeller, the impeller was rotated at the flow rate of $0.75 \mathrm{~mL} / \mathrm{min}$. With the rotating impeller, in order to obtain the applicability at the micromixer, the mixing performance was observed using an optical microscope. At the higher flow rates than 2.25 , the endpoint direction of the outlet was yellow. It means that the fluid is fully mixed at the end of the outlet. At that time, the mixing efficiency was higher than 0.93 . As a result, the two-step hybrid process considering the influence of the refractive index of the glass demonstrates the creation of the more precise and highresolution movable parts inside a glass. The scale-down micromixer is applicable at the low flow rate system.

\section{Acknowledgements}

Not applicable.

\section{Authors' contributions}

JK designed 3D microfluidic device, analyzed the structuring process, and wrote the manuscript. SK fabricated, analyzed 3D microfluidic devices, and wrote the manuscript. Y-HJ analyzed wet etching results. JC improved 3D laser micromachining and reviewed the manuscript. CK supervised the project and reviewed the manuscript. All authors read and approved the final manuscript.

\section{Funding}

This work was supported by the Ministry of Trade Industry and Energy (MOTIE) under the Bilateral International Technology development program (Project No. P0011279).

Availability of data and materials

Not applicable.

\section{Declarations}

Ethics approval and consent to participate

Not applicable.

Consent for publication

All authors agreed to this publication.

\section{Competing interests}

Not applicable.

Received: 11 September 2021 Accepted: 7 December 2021

Published online: 17 December 2021

\section{References}

1. Wlodarczyk KL, Hand DP, Maroto-Valer MM (2019) Maskless, rapid manufacturing of glass microfluidic devices using a picosecond pulsed laser. Sci Rep 9:1-13. https://doi.org/10.1038/s41598-019-56711-5

2. Piruska A, Nikcevic I, Lee SH, Ahn C, Heineman WR, Limbach PA, Seliskar CJ (2005) The autofluorescence of plastic materials and chips measured under laser irradiation. Lab Chip 5:1348-1354. https://doi.org/10.1039/ b508288a

3. Chen Q, Li G, Jin QH, Zhao JL, Ren QS, Sen XuY (2007) A rapid and lowcost procedure for fabrication of glass microfluidic devices. J Microelectromechanical Syst 16:1193-1200. https://doi.org/10.1 109/JMEMS.2007. 902467

4. Wang T, Chen J, Zhou T, Song L (2018) Fabricating microstructures on glass for microfluidic chips by glass molding process. Micromachines 9:1-15. https://doi.org/10.3390/mi9060269

5. Lu B, Zheng S, Quach BQ, Tai YC (2010) A study of the autofluorescence of parylene materials for $\mu$ TAS applications. Lab Chip 10:1826-1834. https:// doi.org/10.1039/b924855b

6. Jin JY, Yoo S, Bae JS, Kim YK (2014) Deep wet etching of borosilicate glass and fused silica with dehydrated AZ4330 and a Cr/Au mask. J Micromechanics Microengineering. https://doi.org/10.1088/0960-1317/24/1/ 015003

7. Bu M, Melvin T, Ensell GJ, Wilkinson JS, Evans AGR (2004) A new masking technology for deep glass etching and its microfluidic application. Sensors Actuators A Phys 115:476-482. https://doi.org/10.1016/j.sna.2003.12. 013

8. Nliescu C, Jing J, Tay FEH, Miao J, Sun T (2005) Characterization of masking layers for deep wet etching of glass in an improved $\mathrm{HF} / \mathrm{HCl}$ solution. Surf Coatings Technol 198:314-318. https://doi.org/10.1016/j.surfcoat.2004.10. 094

9. Wang P, Chu W, Li W, Tan Y, Liu F, Wang M, Qi J, Lin J, Zhang F, Wang Z, Cheng Y (2019) Three-dimensional laser printing of macro-scale glass objects at a micro-scale resolution. Micromachines 10:1-9. https://doi. org/10.3390/mi10090565

10. Marcinkevicius A, Juodkazis S, Watanabe M, Miwa M, Matsuo S, Misawa H, Nishii J (2001) Femtosecond laser-assisted three-dimensional microfabrication in silica. Opt Lett 26:277-279

11. Choi J, Schwarz C (2020) Advances in femtosecond laser processing of optical material for device applications. Int J Appl Glas Sci 11:480-490. https://doi.org/10.1111/ijag.14979

12. Hnatovsky C, Taylor RS, Simova E, Rajeev PP, Rayner DM, Bhardwaj VR, Corkum PB (2006) Fabrication of microchannels in glass using focused femtosecond laser radiation and selective chemical etching. Appl Phys A Mater Sci Process 84:47-61. https://doi.org/10.1007/s00339-006-3590-4

13. Song C, Yu B, Wang M, Qian L (2015) Rapid and maskless nanopatterning of aluminosilicate glass surface via friction-induced selective etching in HF solution. RSC Adv 5:79964-79968. https://doi.org/10.1039/c5ra13049b

14. Crespi A, Osellame R, Bragheri F (2019) Femtosecond-laser-written optofluidics in alumino-borosilicate glass. Opt Mater X 4:100042. https://doi. org/10.1016/j.omx.2019.100042

15. Bischof D, Kahl M, Michler M (2021) Laser-assisted etching of borosilicate glass in potassium hydroxide. Opt Mater Express 11:1185. https://doi.org/ 10.1364/ome.417871 
16. Chen L, Yu D (2021) Investigation of low-cost through glass vias formation on borosilicate glass by picosecond laser-induced selective etching. J Mater Sci Mater Electron 32:16481-16493. https://doi.org/10.1007/ s10854-021-06205-w

17. Butkute A, Baravykas T, Stančikas J, Tičkūnas T, Vargalis R, Paipulas D, Sirutkaitis V, Jonušauskas L (2021) Optimization of selective laser etching (SLE) for glass micromechanical structure fabrication. Opt Express 29:23487. https://doi.org/10.1364/oe.430623

18. Loturco S, Osellame R, Ramponi R, Vishnubhatla KC (2013) Hybrid chemical etching of femtosecond laser irradiated structures for engineered microfluidic devices. J Micromechanics Microengineering. https://doi. org/10.1088/0960-1317/23/8/085002

19. Kim S, Kim J, Joung YH, Ahn S, Park C, Choi J, Koo C (2020) Monolithic 3D micromixer with an impeller for glass microfluidic systems. Lab Chip 20:4474-4485. https://doi.org/10.1039/d0lc00823k

20. Kim S, Kim J, Joung YH, Ahn S, Choi J, Koo C (2019) Optimization of selective laser-induced etching (SLE) for fabrication of 3D glass microfluidic device with multi-layer micro channels. Micro Nano Syst Lett. https://doi. org/10.1186/s40486-019-0094-5

21. Hermans M, Gottmann J, Riedel F (2014) Selective, laser-induced etching of fused silica at high scan-speeds using $\mathrm{KOH}$. J Laser Micro Nanoeng 9:126-131. https://doi.org/10.2961/jlmn.2014.02.0009

22. Sugioka K, Cheng Y (2014) Ultrafast lasers-reliable tools for advanced materials processing. Light Sci Appl 3:1-12. https://doi.org/10.1038/lsa. 2014.30

23. Gottmann J, Hermans M, Repiev N, Ortmann J (2017) Selective laserinduced etching of 3D precision quartz glass components for microfluidic applications-up-scaling of complexity and speed. Micromachines. https://doi.org/10.3390/mi8040110

24. Lin Z, Xu J, Song Y, Li X, Wang P, Chu W, Wang Z, Cheng Y (2020) Freeform microfluidic networks encapsulated in laser-printed 3D macroscale glass objects. Adv Mater Technol. https://doi.org/10.1002/admt.201900989

25. Sugioka K, Xu J, Wu D, Hanada Y, Wang Z, Cheng Y, Midorikawa K (2014) Femtosecond laser 3D micromachining: a powerful tool for the fabrication of microfluidic, optofluidic, and electrofluidic devices based on glass. Lab Chip 14:3447-3458. https://doi.org/10.1039/c4lc00548a

\section{Publisher's Note}

Springer Nature remains neutral with regard to jurisdictional claims in published maps and institutional affiliations.

\section{Submit your manuscript to a SpringerOpen ${ }^{\odot}$ journal and benefit from:}

- Convenient online submission

- Rigorous peer review

- Open access: articles freely available online

- High visibility within the field

- Retaining the copyright to your article 